\title{
MIGRACIÓN MEXICANA A ESTADOS UNIDOS. NOTAS PARA UNA SOLUCIÓN
}

\author{
Por \\ Samuel Schmidt*
}

\begin{abstract}
RESUMEN
La desigualdad económica existente entre los países del primer mundo y los llamados en vías de desarrollo, se ha visto incrementada con las reestructuraciones económicas neoliberales. El fenómeno migratorio, visto como un reflejo de esta descomposición económica, es un asunto que concierne no sólo a los países expulsores, sino también a los países "desarrollados", quienes han evadido su responsabilidad y deciden enfrentar la migración con medidas de tipo policiaco.

Desde esta perspectiva, en este trabajo se exploran las diversas dimensiones en las que se desenvuelve la migración mexicana hacia los Estados Unidos, asunto que requiere ser analizado desde la óptica de derechos humanos. Se hace además, una revisión de los posibles efectos que el TLC traerá sobre los flujos migratorios y para finalizar, se proponen algunas recomendaciones encaminadas a resolver esta cuestión.
\end{abstract}

\begin{abstract}
The economic inequality existing between first-world countries and those said to be in a state of development, has been viewed as incremented with neoliberal economic restructuring. The migration phenomenon, taken as a reflection of this economic upheaval, is something which concerns not only those countries which emigrants are forced to leave, but also the "developed" coutries, which have evaded their responsability, and decided to deal with immigration by means of police action. From this perspective, this essay explores the various aspects of Mexican emigration to the United States, which must be analyzed from the human rights point of view. There is also a look at the possible future effects of the FTA on migratory flow. Finally, some recommendations that might lead toward the resolution of this situation are proposed.
\end{abstract}

\section{INTRODUCCIÓN}

La migración masiva es el síntoma de una descomposición económica de grandes dimensiones. Usualmente es el resultado de problemas de salud

* Universidad de Texas en El Paso. 
pública, deterioro de recursos naturales, erosión del suelo, daño ambienta. y problemas políticos. ${ }^{1}$

La sedentarización del ser humano estableció la premisa de que el individuo puede progresar y desarrollarse sin realizar grandes movimientos, es por esto que intrigan las causas que motivan una migración en masa. Históricamente los conglomerados humanos se han movido huyendo de las inclemencias de la naturaleza o de los horrores de la guerra y la persecusión, luego entonces cómo explicar una migración masiva cuando ninguna de estas calamidades existe si no es que existe la búsqueda de mejores oportunidades económicas y sociales.

La migración que está recibiendo el norte desarrollado, desde Europa hasta Estados Unidos, responde a las condiciones de miseria extrema en la que el norte ha sumido al sur. Esta condición de miseria arranca desde las ocupaciones coloniales y continúa con las restructuraciones económicas neoliberales que han continuado sangrando la economía de los países que eufemísticamente se llaman en vías de desarrollo. Los países "desarrollados" se niegan a aceptar su responsabilidad en la creación de este cuadro económico y ante mejores opciones, desarrollan medidas policiacas para enfrentar un problema socioeconómico, que genera tensiones políticas y ya ha adquirido tonalidades de discriminación y violación sistemática de los derechos humanos.

El migrante mexicano (al igual que los centroamericanos, norafricanos y otros) vive una situación lo suficientemente desesperada como para correr la aventura de migrar hacia el norte, con el costo de dejar atrás terruño, familia, cultura, idioma y con el riesgo que implica arrastrar el acoso, la persecusión y el abuso de las policías de ambos países. ${ }^{2}$

Es justamente en la perspectiva de la descomposición económica y sus consecuencias demográficas, urbanas, jurídicas y políticas como hay que analizar las causas y efectos de la migración mexicana a Estados Unidos, para entender por qué representa un factor de irritación en las relaciones entre México y Estados Unidos. Para esto exploraremos las diversas dimensiones en las que se desenvuelve la migración, pasaremos por los posibles efectos que tendrá el Tratado de Libre Comercio (TLC) sobre la

1 Un estudio sobre África que no deja de impresionar por el trazo de una situación compartida por muchos países del mundo, se encuentra en el trabajo de Robert D. Kaplan, "The Coming Anarchy" (1994).

2 Europa ha generado soluciones policiacas a la migración. En el caso de los migrantes centroamericanos el cuadro es todavía más drástico porque sufren abuso de varios cuerpos policiacos. Existen denuncias de violación sitemática a las mujeres controamericanas que cruzan México. Hay una dramatización al respecto en la película El Norte. El fenómeno centroamericano es distinto al mexicano y al igual que la problemática de los derechos humanos, su tratamiento está lejos del objeto de este artículo. 
migración y terminaremos haciendo varias recomendaciones para resolver la cuestión de la migración.

\section{LA DIMENSIÓN CUANTTTATIVA}

Si bien la migración mexicana a Estados Unidos tiene una larga historia, ${ }^{3}$ conviene empezar a explorarla desde 1942 cuando se firmó el primer convenio laboral entre ambos países. En ese entonces se instauró el Programa Bracero para "importar" temporalmente trabajadores agrícolas. Hacia el funal del programa en 1964, más de 4.5 millones de mexicanos habían trabajado temporalmente en Estados Unidos (Vernez, 1991:1189). Muchos de estos trabajadores fueron contratados más de una vez, por lo que esta cantidad no implica necesariamente personas distintas.

Si bien el programa bracero estaba pensado para resolver la carencia de mano de obra de Estados Unidos debido a la guerra, no absorbió el excedente de mano de obra mexicana, ya que desde entonces el mayor nivel salarial de Estados Unidos atraía mexicanos y tampoco frenó la migración indocumentada. Durante su vigencia 33\% de las personas deportables eran mexicanos y solamente en 1954 fueron deportados un millón de inmigrantes indocumentados. A la fínalización del programa, la cantidad de mexicanos deportables aumentó. En 1961 había 29817 mexicanos deportables representando el $33.6 \%$ del total de personas deportables. Para 1976, éstos llegaban a 781474 representando $89.2 \%$ del total de personas deportables ${ }^{4}$ y en los noventa la patrulla fronteriza ha detenido arriba de un millón de mexicanos al año.

Muchas de las cifras sobre la migración indocumentada son dudosas, ${ }^{5}$ lo cual ha llevado a manipulaciones de las cifras con serias consecuencias políticas, facilitando que se caiga en la trampa de las grandes cifras sin notar que muchas veces se utilizan cantidades convencionales de dudoso origen. El Servicio de Inmigración y Naturalización (SIN) acepta que los factores que se utilizan para calcular el número de mexicanos indocumentados en Estados Unidos no tienen ningún soporte científico. ${ }^{6}$

\footnotetext{
1. Muchos fronterizos recuerdan que no hace mucho tiempo cruzaban libremente entre ambos paises.

4 Diez Canedo, en su trabajo La migración indocumentada de México a los Estados Unidos. ('n nuevo enfoque (1984:30) también considera a la migración como un problema económico.

La misma problemática se presenta en España, donde con base en datos inflados los medios ik comunicación alimentan una actitud antiinmigrante prejuiciada que linda en el racismo. (lzquierdo, 1992).

Entrevista con Alfred Giugni, marzo 30 de 1993. Más adelante se hace referencia a los números en cuestión.
} 
Hay evidencias de que el guessestimate (adivinanza) ha predominado en el cálculo de los mexicanos que viven en Estados Unidos y de los inmigrantes indocumentados. En 1975, un grupo de panelistas sin más bases que sus opiniones personales, estimó que habían 8180000 mexicanos en Estados Unidos (Diez-Canedo, 1984:31). Hoy en día se calcula que de los 25 millones de latinos reportados por el censo, $60 \%$ son de origen mexicano. De ser ciertas las cifras, esto representaría $183.4 \%$ de incremento en solamente 15 años.

Lo mismo sucede con las cifras oficiales. La patrulla fronteriza insiste en que los detenidos representan individuos distintos y no eventos. Esta elevación artificial de los números ha aumentado su presupuesto e inflamado sentimientos antimexicanos. Lo preocupante es que sobre esas estimaciones, se han sustentado estudios cuyo efecto tremendista ha tenido un impacto negativo en la relación binacional y ha politizado de manera inadecuada la cuestión de la inmigración. Entre otras consecuencias, el registro de un número elevado de migrantes mexicanos ha justificado el criterio de militarizar la frontera.

La patrulla fronteriza reporta la detención de arriba de 1.1 millones de personas anualmente (cuadro 1) y calcula que por cada detenido tres se logran introducir, esto da un total de 3.3 millones, que sumados al 1.1 nos da 4.4 millones. Si este número fuera cierto casi el $5 \%$ de la población total de México estaría emigrando hacia Estados Unidos anualmente.

El SIN modifica esta cifra considerando que los detenidos realizan en promedio cinco intentos, lo cual reduce el número a 880000 cifra que parecen aceptar las autoridades migratorias mexicanas.

Un estudio reciente acepta el dato de detenidos por la patrulla fronteriza, aplica la convención de tres introducidos por cada detenido, pero establece 2.8 intentos de cruce por cada detenido, lo que resultaría en 1571428 migrantes indocumentados (Santibáñez, 1993).

El número de mexicanos que ha emigrado legalmente a Estados Unidos ha aumentado notablemente. La redistribución de cuotas de inmigración de países que no las ocupaban beneficiaron básicamente a México y Filipinas, facilitando la legalización de personas que vivían en el país e incrementando la migración de sus familiares. Como resultado de la Ley Simpson-Rodino, entre 1986-1987, 3.1 millones de mexicanos cuya estancia en Estados Unidos era por lo menos de cinco años, legalizaron su situación migratoria. Las nuevas cuotas facilitaron que 1625235 mexicanos emigraran legalmente entre 1990-1991? Si agregamos la

7 Según datos del Departamento de Justicia, Servicio de Inmigración y Naturalización de los Estados Unidos. INS Fact Book (1993). 
Cuadro 1. Aprehensiones en la frontera México-Estados Unidos.

\begin{tabular}{lrrrrr}
\hline Año & $90^{\mathrm{a}}$ & \multicolumn{1}{c}{91} & 92 & 93 & $94^{\mathrm{b}}$ \\
\hline Total frontera & & & & & \\
México-EUA & 206920 & 1081850 & 1134332 & 1182912 & 647229 \\
Marfa & 1587 & 10837 & 33764 & 42778 & 98971 \\
McAllen & 16376 & 86186 & 86390 & 115259 & 81376 \\
Del Río & 4823 & 38746 & 33192 & 43738 & 33540 \\
El Paso & 35836 & 142048 & 179410 & 158070 & 31787 \\
Yuma & 6997 & 26798 & 23652 & 23665 & 14072 \\
Tucson & 9704 & 61406 & 73544 & 98802 & 89890 \\
San Diego & 101475 & 544466 & 544576 & 88930 & 47106 \\
El Centro & 6504 & 30435 & 29326 & 30371 & 17549 \\
\hline
\end{tabular}

FUENTE: Patrulla Fronteriza.

${ }^{\text {a }}$ De octubre a diciembre.

${ }^{\mathrm{b}}$ De enero a julio.

migración legal desde 1986 al escenario bajo de migrantes indocumentados calculado con base en los cinco intentos de cruce, hasta 1993, en seis años tenemos un total de 7180000 migrantes que representan arriba de $8.75 \%$ de la población. Esto explica el bajo desempleo reportado por el gobierno mexicano (alrededor de $7 \%$ en 1995). Si anualmente se incorporan 1.1 millones al mercado de trabajo y durante un año emigró más de un millón y medio, entonces hay una pérdida neta de más de 400000 personas. Si esta tendencia continúa, puede haber varias consecuencias: el mercado de trabajo puede registrar escasez de mano de obra, se generará desequilibrio en el mercado de trabajo, despoblación de áreas completas o habrá ausencia de conflicto al generarse desempleo. Si las consecuencias pueden ser favorables para la estabilidad política, socialmente se pierde población emprendedora y aventurera, que tanta falta hace para atacar iniciativas nacionales.

La calidad de la migración mexicana también está cambiando. El migrante tiene cada vez mayor nivel educativo, están migrando familias y en lugar de ir y venir parecen estar dispuestos a quedarse en Estados Unidos (Vernez y Ronfeldt, 1991).

La población migrante en Estados Unidos se agrupa geográficamente. El $93.1 \%$ de la población hispana se concentra en tres estados. En Califomia representan $25.8 \%$ de la poblacion, en Texas $25.5 \%$ y en Florida $12.2 \%$. En Florida posiblemente una gran mayoría son cubanos, pero en los otros dos estados son de origen mexicano. Estas cifras crean una 
composición étnica que requiere provisión de servicios educativos y electorales en el idioma de la mayor minoría étnica. Pero más que nada, puede implicar un rompimiento de los controles políticos locales, ya que al cambiar el grupo étnico mayoritario también lo hacen las lealtades y los acomodos de poder. Esto si bien es un escenario optimista para los hispanos, es poco realista, ${ }^{8}$ pero no obstante ha servido para inflamar sentimientos antimexicanos en Estados Unidos.

\section{LA DIMENSIÓN ECONÓMICA}

La gran corriente migratoria de México hacia Estados Unidos es la expresión manifiesta del grado de miseria que hay en México y del nivel de desesperación al que han llegado millones de personas que no pueden resolver sus problemas económicos en sus lugares de origen.

De los treinta y dos estados de la república mexicana, dieciocho expulsan población. En la década de 1980 a 1990, algunos estados tuvieron una pérdida migratoria superior a $15 \%$, es el caso de Guerrero $(15.2 \%)$, Michoacán (17.2\%), Oaxaca (17.6\%), Hidalgo (18.0\%) Durango (18.8\%) y Zacatecas (33.8\%). En un estudio hecho en la zona de San Diego en enero de 1992 por el SIN, se encontró que 52\% de los mexicanos detenidos provenían del Distrito Federal, Jalisco, Michoacán y Guerrero (Servicio de Inmigración y Naturalización de los Estados Unidos, s/f:4).

Zacatecas y Durango envían población a Estados Unidos desde la década de los treinta, pero a partir de los setenta la migración mexicana se ha incrementado en forma paralela al nivel de miseria de los mexicanos. En Los Ángeles la Federación de Clubes Zacatecanos reportaba en 1993 la existencia de una comunidad de casi 250000 personas.

El "milagro mexicano" que arrancó en los años cuarenta, dejó una secuela de miseria muy marcada. Desde 1963 se registraban 30 millones de pobres de los cuales 24 vivían en extrema miseria. El encargado del programa alimentario de José López Portillo dijo en 1980: "No esperamos dejar fuera de la modernización a los 20 millones de marginados, no solamente porque es una cuestión de justicia, sino porque además existe la necesidad de incrementar el mercado." (Casio, 1980:22). Hacia $1984 \mathrm{el}$ número de mexicanos en miseria extrema se redujo, pero a partir de ese año empezó a elevarse. Para 1990, el número de pobres ascendió a 51

8 Casi $70 \%$ de la población en El Paso es hispana, sin embargo hasta la elección de 1996 el congresista es anglo, el alcalde es anglo y en abril de 1994 la juez del condado que era hispana, fue derrotada por un anglo. En 1996, después de la jubilación del congresista Ronald Coleman por fin el congresista es hispano. 
millones, de los cuales 19 millones vivían en miseria extrema. Solamente un año después los números se incrementaron a 55 y 20 respectivamente (Balboa, 1991:4-5).

Balboa (1991), citando el Programa de Capacitación y Productividad de la Secretaría del Trabajo y Previsión Social, considera que en 1991 había 12 millones de trabajadores en miseria, pero considerando a sus dependientes, el número asciende a 34 millones de personas. La Comisión Económica para América Latina (CEPAL) sostiene que el número de mexicanos en la miseria llegó a 13.6 millones en 1992 (Sainz, 1993:30-31). Corro reporta que en 1989, el $16.2 \%$ de la población o 12730734 vivían en la pobreza extrema. Para 1992 aumentaron a 25496582 que representaban 30.1\% de la población (Corro, 1993:30-31).

Esta agravación de la miseria ha sido parcialmente responsabilidad del gobierno, ya que siguiendo la tesis de que el factor trabajo es el que más inflación provoca, estableció una política de freno al ingreso fijo y amplió el número de pobres y la calidad de la pobreza. En un estudio realizado por un equipo de economistas del Centro de Análisis de la Facultad de Economía de la UNAM, se calcula que "en 1977 el $57.9 \%$ de la población sobrevivía en la pobreza, en la actualidad [1993] la cifra es de $91.9 \%$, o sea que 78 milliones de mexicanos no pueden cubrir sus mínimas necesidades." Según este estudio, desde 1982, año en que Salinas de Gortari se hizo cargo de la política económica del régimen hasta 1993, el salario mínimo aumentó en $409 \%$ pero el precio de la canasta básica integral (CBI) que está formada por 312 bienes y servicios de consumo y uso diario para una familia de cinco personas, aumentó en $1388 \%$. En 1982, el salario mínimo alcanzaba para adquirir $38 \%$ de la CBI, pero en 1993 alcanzaba para adquirir solamente $13 \%$ (Corro, 1993),

Siguiendo el análisis de Martínez (1989;46), el salario mínimo real alcanzó un máximo en 1976 para empezar a declinar y llegar en 1985 a situarse en los niveles de 1966, siendo inferior en $25.1 \%$ al de 1970 y en $40.1 \%$ al de 1976. Es así como el salario mínimo se redujo al nivel de una generación anterior. En términos agregados, la aportación del trabajo al Producto Interno Bruto (PIB) disminuyó de $37.4 \%$ en 1981 a $26.4 \%$ en 1986, mientras que en Estados Unidos se mantenía constante (Martínez, 1989:37-38). Si consideramos que el salario real ha continuado cayendo, incluida su debacle de 1993 (Banamex, 1993:330), tenemos que los mexicanos han perdido más de una generación y no una década como comúnmente se considera.

Otros acercamientos nos muestran el costo social de este cuadro. Según el XI Censo general de población y vivienda ${ }^{9}$ de 1990 , el $12.4 \%$ de la población era analfabeta, $36.4 \%$ de las viviendas carecían de drenaje, 
$20.6 \%$ de agua entubada y $12.5 \%$ de energía eléctrica. La Asamblea de Representantes de la Ciudad de México rebelo que 34\% de los niños mexicanos tienen una estatura y peso abajo de lo normal y la tasa de mortalidad infantil es de 12 por cada mil nacimientos (Morales, 1993:19),

Ante esta realidad, el gran diferencial económico entre ambos países funciona como un gran imán que atrae a aquéllos que tienen oportunidades insatisfechas. ${ }^{10}$ No es de extrañar entonces que los mexicanos revisaran las historias de éxito de sus compatriotas que vivieron el programa bracero y voltearan hacia el norte (Herrera, 1979). El reporte del servicio de inmigración mencionado consigna que $79 \%$ de los inmigrantes estudiados tenía empleo antes de migrar, aunque ganaban un promedio de 34.36 dólares semanales (Servicio de Inmigración y Naturalización de los Estados Unidos, s/f:4). Ganando salario mínimo en Estados Unidos con sólo trabajar ocho horas se ganaría lo que en una semana en México.

\section{NEOLIBERALISMO Y CONCENTRACIÓN DE LA RIQUEZA}

La contraparte de la miseria extrema es la concentración de la riqueza extrema, que históricamente ha estado concentrada en unas cuantas manos, aunque se ha agravado en los últimos doce años. La estrategia del gobierno ha sido facilitar la elevación de las ganancias para que luego se inviertan. Desafortunadamente, solamente la primera parte de la ecuación funciono, porque las ganancias se invirtieron en proyectos suntuarios que no produjeron desarrollo o se fugaron del país.

Los millonarios mexicanos que no sostienen un proyecto de desarrollo nacional, tienen la capacidad de hacer donativos millonarios en dólares para los partidos políticos hasta el grado de sorprender a los mexicanos (Rodríguez, 1993) y a la opinión pública internacional (McClintock, 1993:4A). No son menos sorprendentes los cálculos de fuga de capital. ${ }^{11}$ En lo más álgido de la crisis mexicana, en 1987, el capital fugado era

9 Las datos preliminares del censo fueron cuestionados porque aparentemente se había contado muy baja la población de prácticamente todas las ciudades. $\mathrm{Si}$ a los resultados globales del censo le agregamos la migración documentada e indocumentada posiblemente lleguemos muy cerca de las proyecciones que se habían realizado. En el plano local, aparentemente el error consiste en que no se contaron los "asentamientos irregulares" que en muchos casos casi igualan el número de habitantes de la ciudad. En Ciudad Juárez, Chihuahua se calcula existen 300 colonias irregulares, y según las autoridades municipales hay casi 500000 personas más de las 750000 reportadas por el censo.

10 En 1996 el salario mínimo en Estados Unidos era casi diez veces superior al mexicano.

11 No existe ninguna fuente que establezca los montos que huyeron de México y otros países latinoamericanos. Solamente durante 1976, año en que la deuda total era de 19600 millones, salieron del pais 27296 millones (Schmidt, 1991:179). De 1976 a 1984 salieron 27000 millones (Jeffrey A. Frieden, 1989:31). 
superior a los 107470 millones de dólares de deuda total (Gurría, 1991:15). Muchos mexicanos han sostenido por muchos años el mercado de bienes raíces en el sur de Estados Unidos. Ya sea en tono de broma o de preocupación, en los setenta la gente llamaba al centro de veraneo texano, South Padre Island, Nuevo León ${ }^{12}$ o identificaba a dos elegantes torres en Coronado, California como las Taco Towers. Con frecuencia mientras el mercado de bienes raíces pierde valor en Estados Unidos, en las ciudades fronterizas estadounidenses o lo mantiene o se eleva.

Durante muchos años los economistas hicieron llamadas de atención contra los efectos perniciosos que tendría el continuar la concentración de la riqueza. En los 19 años de 1950 a 1969, 20\% más alto de la población elev6 en $4 \%$ la porción que controlaba del ingreso nacional para llegar a $64 \%$, lanzando hacia el nivel de miseria al $70 \%$ más bajo de la población. El gran proyecto petrolizador de fin de los setenta y principios de los ochenta contribuyó a agravar el cuadro distributivo.

En los noventa, el gobierno abrazó al neoliberalismo buscando una alianza con los republicanos en Estados Unidos con la esperanza de que esto generara un gran flujo de inversiones hacia México. Esto sucedió aunque volvió a la economía más vulnerable que nunca antes, hizo más dependiente a México de Estados Unidos y polarizó más la concentración del ingreso, generando un puñado de super ricos y una masa de super pobres, que no solamente es para avergonzarse sino que puede considerarse una tragedia nacional.

La privatización del sector estatal de la economía llevado a cabo entre 1982 y 1994 oligarquizó a México, al grado que 38 familias, miembros del Consejo de Hombres de Negocios, poseen setenta grupos económicos cuyas ganancias equivalen a $73 \%$ de las ganancias de todas las empresas que cotizan en la bolsa de valores (Acosta, 1992:18-30). Estas familias se aprestan a hacer de la economía mexicana su instrumento personal de acumulación de riqueza con muy poca preocupación por los efectos sociales de tal acumulación. Finalmente, mientras cuenten con un gobiemo autoritario podrán continuar con el mismo modelo. ${ }^{13}$

\footnotetext{
${ }^{12}$ En sus memorias Luis M. Farías, ex gobernador de Nuevo León menciona: "Dicen que para ser regiomontano hay que tener una casa en la Isla del Padre, si no, no es regiomontano, porque le piden a uno una casa allí para registrarse como candidato en Monterrey". (Farías, 1992:170).

Hay múltiples seńales de agotamiento del modelo de gobierno y su capacidad de control. Entre otras, una fuerte oleada de secuestros que desde 1993 han hecho presa a la sociedad mexicana, el más destacado es el del socio mayoritario de Banamex; un brote de guerra civil en Chiapas el primero de enero de 1994; el asesinato del candidato del PRI en marzo y del secretario general del mismo partido en septiembre de ese mismo año. Sin embargo, el análisis del modelo económico y su relación con el modelo político están lejos del propósito del presente artículo.
} 
El neoliberalismo ha impulsado a las grandes corporaciones mexicanas, algunas de las cuales se expanden intemacionalmente, ${ }^{14} \mathrm{El}$ capital y el trabajo encuentran en el exterior el ámbito para la solución a sus necesidades, las de acumulación de riqueza por un lado y las de empleo $\mathrm{y}$ un ingreso más elevado.

La migración parece ser más benéfica en términos binacionales. Contribuye a la economía mexicana por medio de remisiones que ascienden a varios miles de millones de dólares al año (Lozano, 1993). En Estados Unidos realizan trabajos que los estadounidenses no quieren hacer, con los bajos salarios ayudan a mantener la inflación baja y una alta productividad y vía su consumo o pago de impuestos, que rebasan el valor de los servicios obtenidos, ayudan a reproducir la economía estadounidense. Los migrantes son jovenes y fuertes, por lo que sus demandas al sistema de bienestar social son prácticamente inexistentes. En contra del argumento de que defraudan y abusan del sistema de bienestar social, los mexicanos carecen de acceso al mismo, dado que para recibir servicios como el seguro médico Medicaid, bonos alimentarios, ayuda para familias con hijos, se requiere ser residente legal. Si bien hay fraude en el sistema de bienestar que cuesta miles de millones de dólares, los funcionarios han sido incapaces de frenarlo porque lo cometen los ciudadanos. ${ }^{15}$

El argumento de las autoridades californianas, tal vez las más antimexicanas, en el sentido de que los migrantes les cuestan es falso. La ciudad de Los Ángeles tal vez no reciba lo que quisiera recibir, pero esto es explicable. Los migrantes "generan 18 veces más recursos al gobierno federal, nueve veces más al estado de California y 2.5 veces más a entidades locales distintas al condado de Los Ángeles (Simon, 1993). Si Los Ángeles no se beneficia, sí lo hacen otras ciudades en el mismo condado o en condados adyacentes.

En su argumentación antimexicana, el gobierno californiano omite información sobre el superávit que tiene el sur del estado fronterizo en su intercambio con México. Una fuente más de ingresos para los gobiernos estadounidenses locales es el impuesto predial que entre otras cosas incluye el financiamiento para las escuelas. Muchos mexicanos poseen propiedades en Estados Unidos, y contribuyen para las escuelas aunque no hagan uso de ellas porque viven en México. Y una fuente adicional de

\footnotetext{
14 Uno de los ejemplos más claros es Televisa que en los últimos años ha realizado fuertes jnversiones en Estados Unidos, Perú, Argentina y Venezuela.

13. Gregory Spears, en contra del título de su trabajo "Feds Offer Plan to Combat Billions in Welfare Fraud." no reporta en éste nìngún plan, solamente lista las árcas de abuso más frecuente. (Spears, 1994).
} 
recursos, son los mexicanos que viven en Estados Unidos y trabajan en México, con lo cual trasladan sus ganancias hacia Estados Unidos, depositan su dinero en bancos estadounidenses y ayudan a dinamizar la economía en general. Tal vez sería conveniente que los políticos estadounidenses contabilizaran bien estas contribuciones antes de continuar atizando el fuego del racismo antimexicano. $O$ que los mexicanos comprendieran su peso económico y lo aplicaran para obligar a los políticos a reestructurar su discurso político.

\section{LA DIMENSIÓN SOCIAL}

México no es solamente un país polarizado entre pobres y ricos, sino también entre ciudades con recursos pobres y campo paupérrimo. La miseria rural es básicamente la causa de que en sólo unas décadas $72 \%$ de la población sea urbana. Esta migración interna no se debio a la maravilla de las ciudades o a que ofrezcan múltiples oportunidades, sino al cuadro desastroso que presenta el desatendido campo.

La mala distribución del ingreso también se registró en el campo, A fin de los sesenta el $86 \%$ de los predios arables eran menores a 5 hectáreas donde se concentraba $80 \%$ del trabajo agrícola que registraba una productividad por trabajador de 213 dólares, comparados con los 2300 dólares en el resto de la economía. Del salario mínimo ni que hablar, porque a muchos trabajadores agrícolas se les escamoteaba y otros eran propietarios de mini parcelas. El desgaste de estas parcelas hizo que fueran insuficientes para satisfacer las necesidades básicas de los campesinos.

La ciudad atrajo a una población sin oportunidades en el campo, aunque la infraestructura urbana no tenía la capacidad de absorberlos. Las ciudades crearon islas de pobreza y se convirtieron en focos de riesgo de salud, centros con problemas ambientales e infraestructura deficiente (World Bank, 1991).

Los empleos que los migrantes encontraron, cuando existían, eran mal pagados, teniendo un gran diferencial desventajoso con los de Estados Unidos. No es de sorprender que el paso siguiente fuera dirigirse bacia el norte, desarrollándose así un ciclo migratorio cuya ruta evita las ciudades y se dirige directamente a Estados Unidos. El caso de los indios mixtecas de Oaxaca es aleccionador. En un solo distrito electoral más de 60000 mixtecos han salido, creando lo que parecen ser dos ciclos combinados. En el primero, los trabajadores "golondrinos" se desplazan hacia los estados agrícolas de Sinaloa y Sonora y después de la pizca vuelven a sus parcelas para prepararlas y dejar a las mujeres a cargo. El otro ciclo registra una migración hacia Baja California donde han creado importantes 
colonias desde las que migran hacia el norte volviendo a las colonias en Baja California, especialmente a Tijuana. Han creado asentamientos en Estados Unidos, en Baja California y Oaxaca y se mueven entre ellos. Los zacatecanos, como ya se menciono, han creado una Federación de clubes que tiene una elevada capacidad de organización social y cuenta con 250000 miembros en Los Ángeles. En 1993, acordaron con la Secretaría de Desarrollo Social (SEDESOL) que enviarían dinero a Zacatecas para financiar proyectos y por cada dolar de ellos la SEDESOL pondría dos. Para marzo de 1994 ya habian reunido $\$ 600000$ que estaban en espera de la liberación de los fondos en México para ser enviados.

El mexicano en las ciudades estadounidenses reproduce el mismo patrón de hacinamiento y marginalidad que en las ciudades mexicanas - la mayoria de los damnificados en el terremoto de marzo de 1994 en Los Ángeles fueron mexicanos-, creando concentraciones de pobreza en las que se desarrollan riesgos de salud pública y focos de violencia urbana.

Las redes sociales apoyan la migración y facilitan la integración, pero no en todos los casos los migrantes mexicanos corren con suerte. En El Paso se encontró una migración de niños que no tenían familias en la frontera. En San Diego se encontró un grupo de niños que vivían de prostituirse en el parque Balboa.

Información anecdotica indica que algunos mexicanos migran aceptando una reducción en su status social. Se escuchan historias de mujeres que siendo programadoras de cómputo en México aceptan trabajo de sirvientas en Estados Unidos, de maestros de escuela que migran para convertirse en pizcadores, o hasta el caso de algún médico que ejercía en Mexicali y pizcaba vegetales en Caléxico.

México está desperdiciando la gran inversión que ha hecho para elevar el nivel de vida de su población. En la migración actual se encuentra un buen número de profesionistas, académicos, científicos, y cuadros calificados cuya calificación servirá a Estados Unidos. Si esta tendencia continúa, México se verá en el futuro con una sociedad polarizada entre una élite muy bien preparada y una masa sin preparación, ya que las capas medias tal vez encuentren un salario más atractivo en el norte.

Un buen número de los mexicanos que permanecen en la frontera, tal vez aprovechando la cercanía con Estados Unidos, se convierten en trabajadores transmigrantes, y han generado familias fracturadas y una condición de pobreza en tierra lejana del ternuño, to cual les complica las cosas aún más.

La migración es fuente de complicaciones sociales. El desmembramiento familiar, causado por la migración de algún miembro de la familia, usualmente el jefe de la misma, parece incentivar a otros familiares 
para migrar y reunirse. Es así que 30\% de los migrantes son niños y $12 \%$ son menores de 5 años. Muchos de estos niños son callejeros que migran a causa de la crisis económica o buscando a sus padres. Según la Organización Intemacional del Trabajo en 1993 había 11000 niños trabajando en Estados Unidos, y aun cuando el número es cuestionado, ${ }^{16}$ no hay duda que la migración ha generado un nivel de descomposición familiar y social de serias dimensiones.

\section{LA DIMENSIÓN URBANA}

En Ciudad Juárez, existen 300 colonias "marginales" que no tienen servicios básicos como son agua potable, alcantarillado, drenaje, abasto, protección contra desastres, y el servicio de recolección de basura es prácticamente inexistente (Schmidt y Lorey, 1994).

La migración está creando cartolandias en la mayoría de las ciudades fronterizas mexicanas y una condición urbana patética en muchas ciudades de Estados Unidos. En la zona de Carlsbad, en San Diego, hay mexicanos que viven en cañones. En otras ciudades siguen patrones de hacinamiento porque es el medio para poder pagar renta. En contra de lo que muchos piensan, sobre el impacto positivo de la cultura estadounidense que se llevarán a México cuando vuelvan, lo cierto es que se llevarán una cultura de pobreza urbana muy similar a la que tenían en México.

El Plan Integral de Protección Ambiental Fronterizo (PIAF) consigna que en la franja fronteriza, 25\% de las familias viven debajo de la línea de pobreza y con riesgos de salud muy serios. En El Paso, Texas, 35\% de los niños antes de los 8 años y $85.9 \%$ de los residentes de hasta 35 años han sufrido de Hepatitis tipo A. Para el valle del Río Bravo que incluye Brownsville, McAllen y Laredo el cuadro es peor. Hay que recordar que los virus, las bacterias y la contaminación no tienen pasaporte ni visa, ni hay autoridad migratoria que logre detenerlos.

Las ciudades mexicanas están limitadas fiscalmente para resolver los problemas y dependen de prioridades y decisiones tomadas en el centro. Así, el sistema fiscal ahoga al país. La Secretaría de Hacienda definió la formula 80-20-20, que consiste en que el gobierno federal se queda con el $80 \%$ de cada peso recaudado, el estado se queda con el $80 \%$ del $20 \%$ enviado por el centro, de tal manera que el municipio solamente recibe 4

\footnotetext{
${ }^{16}$ Datos presentados y cuestionados por Jesús Rodríguez, director de Organismos Internacionales de la Comisión Nacional de Derechos Humanos, en el "Foro de Consulta, Frontera Norte" de la Comisión de Asuntos Fronterizos de la Cámara de Diputados, Monterrey, Nuevo León, abril 13-14 de 1994.
} 
centavos de cada peso fiscal producido. Este sistema dificulta el desarrollo de las ciudades porque las prioridades las fija el gobierno federal. Durante el sexenio 1988-1994 Solidaridad ofreció recursos no presupuestales, pero fij6 las prioridades distorsionando los objetivos de las autoridades municipales.

Las ciudades fronterizas estadounidenses son pobres. El gobierno federal ofrece recursos limitados para los cuales hay que competir nacionalmente. Estos recursos se consiguen por medio de los congresistas o de un cabildeo más o menos organizado y con frecuencia las ciudades fronterizas carecen de ambos, con lo cual sus oportunidades se reducen.

En ocasiones, las autoridades de la ciudad y del condado evaden sus responsabilidades creando áreas grises de responsabilidad administrativa. En El Paso, la ciudad y el condado evaden actuar para resolver la carencia de agua y servicios para el $15 \%$ de la población del condado que carece de ellos porque viven en las así llamadas "colonias", La ciudad argumenta que las colonias están fuera de los límites de la ciudad, y el condado, argumenta que no tiene recursos.

Las ciudades fronterizas cooperan poco entre ellas y muchas veces compiten entre sí debilitándose mutuamente. La migración crea una presión adicional para ciudades que no tienen ni los recursos, ni la capacidad técnica para responder, y teniendo un flujo migratorio constante que no dejará de crecer. Como se ve en el cuadro 2, el cuadro urbano seguirá empeorando.

\section{LA DIMENSIÓN JURÍDICA}

En Estados Unidos la concepción filosófico-jurídica sobre la migración indocumentada es que se trata de una actividad criminal. ${ }^{17}$ Por el solo hecho de cruzar la línea sin documentos el migrante se convierte en criminal. Basadas en esta definición, las policías se entrenan para perseguir criminales y se ensañan contra ellos. La ley de inmigración de 1986 conocida como Simpson-Rodino criminalizó el trabajo, al establecer una cláusula de que en caso de que el trabajador aporte información falsa, como el número de seguro social, comete un crimen.

Esta concepción justifica el establecimiento de bloqueos fronterizos y una política de militarización. Es así como el gobiemo estadounidense gasta más en "proteger" la frontera de los mexicanos, de lo que gasta en mejorar la infraestructura urbana en las ciudades fronterizas.

17 Explore la legislación migratoria estadounidense y la criminalización del trabajo en: "Detentions et deportation a la frontiere entre le Mexique et les Etats-Unis" (Schmidt, 1996). 
Cuadro 2. Crecimiento de las ciudades fronterizas. 1965-2010 (porcentajes).

\begin{tabular}{lrrrrrrrrrr}
\hline Año & 1965 & 1970 & 1975 & 1980 & 1985 & 1990 & 1995 & 2000 & 2005 & 2010 \\
\hline México & 17.51 & 17.51 & 17.73 & 17.73 & 10.13 & 10.21 & 13.61 & 10.13 & 8.95 & 7.93 \\
Tamaulipas & 19.22 & 19.30 & 14.91 & 14.94 & 8.10 & 8.13 & 9.14 & 6.28 & 5.06 & 4.05 \\
Matamoros & 32.96 & 22.15 & 17.00 & 17.08 & 18.71 & 18.76 & 11.93 & 12.43 & 10.87 & 9.38 \\
Reynosa & 36.11 & 36.14 & 18.99 & 19.06 & 16.89 & 18.87 & 16.14 & 11.86 & 9.66 & 7.73 \\
Nuevo Laredo & 26.72 & 26.82 & 16.37 & 16.41 & 4.01 & 4.11 & 13.57 & 6.18 & 4.89 & 3.83 \\
Coahuila & 10.78 & 10.86 & 18.13 & 18.22 & 12.53 & 12.54 & 13.56 & 12.96 & 12.53 & 12.07 \\
Piedras Negras & -4.70 & 5.33 & 28.17 & 28.25 & 19.40 & 17.95 & 6.94 & 15.31 & 15.24 & 15.16 \\
Chihuahua & 14.64 & 14.56 & 11.49 & 11.54 & 10.30 & 10.39 & 12.05 & 10.37 & 9.93 & 9.46 \\
Ciudad Juárez & 24.62 & 24.7 & 12.94 & 29.84 & 20.38 & 20.44 & 15.72 & 17.49 & 16.83 & 16.09 \\
Sonora & 18.42 & 18.43 & 17.34 & 17.41 & 9.70 & 9.81 & 13.99 & 10.03 & 8.84 & 7.72 \\
Nogales & 17.62 & 17.64 & 12.15 & 12.23 & 27.02 & 27.08 & 9.49 & 17.29 & 17.09 & 16.87 \\
Baja California & 20.68 & 29.37 & 16.36 & 16.33 & 18.71 & 18.77 & 14.72 & 13.16 & 11.40 & 9.73 \\
Mexicali & 27.83 & 22.89 & 13.80 & 13.90 & 13.25 & 13.32 & 10.64 & 10.19 & 8.87 & 7.63 \\
Tijuana & 34.90 & 34.90 & 24.44 & 24.46 & 27.50 & 27.59 & 19.70 & 19.00 & 16.41 & 13.86 \\
\hline & & & & & & & & & & \\
\hline & & & & & & & & & \\
\hline
\end{tabular}

FUENTE: INEGI. Catálogo general de población y vivienda. Varios años.

Las cortes comparten esta concepción de la administración federal, lo que complica el cuadro porque politiza decisiones que deberán apegarse estrictamente a la ley. Los jueces en Estados Unidos son electos, lo que los hace sujetos de presión política, especialmente durante coyunturas electorales.

En 1994, año de elecciones, se vio un endurecimiento en las cortes. En Arizona, un jurado declaró no culpable a un agente de la policía fronteriza que mató a un mexicano por la espalda y trató de esconder el crimen. Similar trato recibió en El Paso un policía que abuso de un mexicano. Es de esperar que ante la escalada de intolerancia republicana las cortes se edurezcan enviando un mensaje indulgente a los policías que abusan de los mexicanos indocumentados. De cualquier manera este discurso ha sido eficaz para acorralar a los demócratas que han impuesto una política de endurecimiento, que entre otras cosas está estableciendo muros fronterizos, en ocasiones con el beneplácito mexicano, como sucedio en El Paso, donde el cónsul general declaró que no se aceptaba un muro pero sí una barda de malla ciclónica. 
El gobierno mexicano ha tratado de documentar el número de abusos, los que aparentemente llegaron a 117000 durante 1993 (Hernádez, 1994:1A), y ha creado áreas de protección en sus consulados, pero eso ejerce muy poca presión sobre las autoridades policiacas estadounidenses. En primer lugar, porque el número de abusos reportado parece estar inflado vía el registro múltiple del mismo evento y en segundo lugar, por la no coincidencia de concepciones legales sobre el tema. Para Estados Unidos todos los casos de abuso deben desahogarse en revisiones administrativas $o$ en la corte. En el primer supuesto, la queja debe presentarse ante la agencia cuyo agente abusó, La agencia se investiga a sí misma, con lo cual el quejoso es intimidado, así se evita la presentación de quejas o su investigación adecuada, Muchas veces se llega a arreglos extrajudiciales que se mantienen secretos con lo cual se pierde el récord de las quejas. Otras veces los funcionarios consulares no conocen la ley, no presentan los casos de manera adecuada o no les dan seguimiento.

Para el gobierno mexicano, la definición jurídica de la migración se basa en la libertad de tránsito. Éste asume la postura de que no puede evitar el libre tránsito de sus ciudadanos, lo cual sería válido si se tratara solamente de tránsito nacional, pero en lo internacional hay otras regulaciones. Cuando alguien abandona el país por vía aérea tiene que mostrar documentos, ¿por qué no por tierra? Aún más, hay agentes migratorios mexicanos controlando la nacionalidad de los que llegan a las ciudades fronterizas por avión, y se ha desatado una escalada persecutoria dentro de México contra los migrantes centroamericanos, lo cual muestra cierta inconsistencia. Lo cierto es que esta premisa ha facilitado la evasión del gobierno mexicano sobre el tema, porque si no, hubiera tenido que comprometerse a acordar con Estados Unidos una cierta regulación de la migración. Para reducir las tensiones generadas por la migración ambos gobiemos deben redefinir sus políticas. Clint Smith dice: "debemos dejar de enfocar la inmigración como un asunto de aplicación de la ley y reconocer que las soluciones a largo plazo pueden ser encontradas sólo en el contexto de la creciente interdependencia económica y social." (Smith, 1993).

\section{LA DIMENSIÓN POLICIACA}

La migración mexicana ha sido presa del abuso policiaco en ambos lados de la frontera. Aunada a la concepción jurídica que establece a la migración como cuestión ilegal está la percepción ideológica que ve un delincuente en los pobres y los inmigrantes (Izquierdo, 1992:15).

Por años, las policías mexicanas victimizaron migrantes, al grado que cuando el gobiemo crea el grupo Beta en Tijuana, que reúne agentes de 
diversos cuerpos policiacos prohibiéndole la entrada a las distintas policías a la zona fronteriza, el nivel de criminalidad en la llamada tierra de nadie disminuyó drásticamente.

La creación de un escenario donde los migrantes tienen que cruzar clandestinamente facilitó las condiciones para el surgimiento de criminales que abusan de éstos. En El Paso una banda se dedicaba a asaltar migrantes en el llamado Puente Negro, algo similar existe en San Diego. Esto que es un problema estadounidense, en Estados Unidos pretenden atribuírselo a los mexicanos reforzando la posición policiaca.

La patrulla fronteriza tiene gran impacto económico en comunidades pobres, porque crea empleos fijos, lo que ha ayudado a distorsionar la mentalidad de muchos agentes mexicano-americanos haciéndolos caer en el síndrome del oprimido-opresor. Siendo estos mexicanos los oprimídos del sistema estadounidense, entran a la patrulla fronteriza para convertirse en opresores de sus hermanos del otro lado de la línea fronteriza. Como están imbuidos del espíritu de la defensa de la patria contra los "criminales" indocumentados, desarrollan una persecusion despiadada e inmisericorde, que con frecuencia pisotea la dignidad humana.

Éste es un fenómeno interesante. Para Estados Unidos, el individuo es inocente hasta demostrársele la culpabilidad. Pero los migrantes, por entrar indocumentados son culpables antes de ser detenidos, aunque no haya cometido ningún delito. No es de sorprender entonces que este manejo haya elevado el nivel de abuso en la frontera hasta convertir parte de la cuestion migratoria en un tema de violación de los derechos humanos.

El tradicionalmente elevado nivel de abuso policiaco en la frontera ha creado tensiones binacionales e irritación local al grado de surgir varias iniciativas para crear comités de vigilancia de la patrulla fronteriza. Aun cuando las ciudades no tienen jurisdicción sobre la patrulla fronteriza que es una entidad federal, algunas de ellas, como El Paso, crearon comisiones para supervisarla. La creación de Beta también sirvió para que entre las policías se supervisaran. La respuesta de la patrulla ha consistido en desarrollar diversas estrategias para sellar la frontera. En septiembre de 1993 se estableció la Operación Bloqueo en El Paso, y se establecieron operaciones similares en San Diego y Nogales. Consecuentemente se redujeron los niveles de abuso, aunque no por cambio en la mentalidad policiaca sino por ausencia de migrantes.

Para damos una idea del tipo de violación de derechos humanos y civiles en que incurre la patrulla fronteriza tenemos el caso de un juicio por acoso contra la patrulla que entablaron los estudiantes de la escuela preparatoria Bowie de El Paso, el juez resolvió que ésta tenía que respetar la constitución y no acercarse a la escuela. 


\section{LA DIMENSIÓN POLÍTICA}

Los estados mexicanos que registran los hechos de violencia electoral más notorios, son también los expulsores de población. La migración no ha reducido el nivel de conflicto político, aunque al reducir el nivel de votación pudo haberse aumentado el riesgo de falta de consenso y legitimidad. ${ }^{18}$

En Estados Unidos los mexicanos están políticamente desprotegidos. En parte porque desconocen sus derechos, ya que aun como indocumentados tienen derecho a organizarse y presentar quejas. $\mathrm{La}$ percepción de que estarán temporalmente en Estados Unidos también puede ser un factor inhibitorio para su organización. Y por último, aunque no menos importante, la falta de apoyo de instituciones estadounidenses desestimula y desalienta la organización.

Un factor clave para la falta de organización es la ley del trabajo de Estados Unidos que dificulta la organización y facilita la contratación de empleados en huelga. Para los mexicanos que desarrollan trabajo agrícola podría ser fácil organizarse, aunque tal vez poco efectivo dada su vulnerabilidad frente al excedente de mano de obra mexicana migrante y las amenazas de los patrones de acudir a las autoridades migratorias. Estas amenazas no son del todo falsas dadas las múltiples historias de patrones que delataban a sus empleados para evitar el pago de salarios. Esta actitud patronal podría frenarse con las sanciones a los patrones impuestas por la ley, pero esto no sucede porque el SIN y la patrulla fronteriza evitan aplicarlas ya que prefieren castigar al trabajador. Además están las sospechadas complacencias de la patrulla fronteriza que facilitan la contratación de jomaleros agrícolas en las épocas de mayor necesidad de empleo. Los patrones de cualquier manera gozan de lagunas legales que los protegen contra las sanciones, como por ejemplo, decir que los empleados proveyeron un número falso de seguro social, requisito mínimo para conseguir empleo. ${ }^{19}$

Para los que trabajan en la industria puede haber mejor posibilidad de organizacion, pero los sindicatos estadounidenses no solamente son débiles sino que la mayoría se oponen a la migración privando a los

\footnotetext{
${ }^{18}$ Aunque está lejos del propósito de este artículo, bien podría explorarse la hipótesis de que la migración ha transmitido un espíritu de rebelión ante el fraude electoral, el poder central omnimodo y el autoritarismo.

19 El siN está trabajando para reducir la utilización de documentos falsos, incluyendo equipo electrónico que se instale en los negocios para que los patrones puedan verificar con ellos la veracidad de los documentos. El Congreso y el Senado también están trabajando en este sentido.
} 
mexicanos de su apoyo. El sindicato de costureras, International Ladies Garment Workers Union ${ }^{20}$ es una excepción notable dada su postura de apoyo a la migración. Para los que trabajan sin empleo fijo, sus posibilidades de organización son prácticamente nulas.

La migración mexicana puede tener un importante impacto polftico. La comunidad mexicana en Estados Unidos tiene gran influencia económica, le falta conocimiento y organización para convertir esta influencia en poder político. Electoralmente influirán cuando decidan nacionalizarse y ejercer su derecho al voto, lo cual es remoto por el poco deseo de los mexicanos a nacionalizarse y por la cultura política mexicana que no estimula la participación electoral, La posibilidad de que México cambie su postura ante la doble nacionalidad, facilitando la nacionalización de los mexicanos en Estados Unidos, podría precipitar transformaciones políticas importantes.

Hoy en día ya empiezan a abundar los casos de influencia política de la comunidad mexicano-americana. Henry Cisneros fue alcalde de San Antonio, fungió como enlace con los hispanos para la campaña de Bill Clinton y hoy es secretario de Vivienda y Desarrollo Urbano.

Los alrededor de 13 millones de mexicanos ${ }^{21}$ o de origen mexicano que viven en Estados Unidos se concentran en algunos estados que tienen más votos electorales. ${ }^{22}$ Su tasa de crecimiento es mayor a la del promedio nacional, con lo cual, sumando el crecimiento vegetativo al crecimiento por inmigración, su peso político dentro de una década podrá ser bastante elevado y ser crucial en la resolución de gestas electorales.

El factor político del racismo no tiene un rol menor. Los intereses conservadores en Estados Unidos, de los cuales algunos son abiertamente racistas, ${ }^{23}$ están avanzando aceleradamente creando un clima antimexicano en Estados Unidos bajo el argumento que la migración abusa del sistema de beneficencia y crea una carga excesiva sobre los estadounidenses. En California el gobernador se reeligió atacando la

\footnotetext{
${ }^{20}$ Este sindicato se fusionó en 1995 con otro sindicato que ve desfavorablemente a la migración.

21 Vernez y Ronfeldt en su trabajo "The Current Situation in Mexican Inmigration" (1991:1190) establecen el número en 12.1 millones para 1988.

22 El presidente de Estados Unidos se elige por medio de un sistema en el cual el voto popular se convierte en voto electoral distribuido por estado según la población. El candidato que logra mayoría de votos electorales gana la elección. Se puede dar el caso que un candidato gane con minoría de votos populares pero mayoria de votos electorales. Es por esto que estados como Texas y California, los que mayor población mexicana concentran, tienen mucho peso político.

233 En San Diego, California surgió un grupo al final de los ochenta que iba a "cazar" mexicanos a la línea fronteriza. Un juez de California declaró inocentes de crímenes de odio a dos personas que golpearon a barazos a unos mexicanos.
} 
migración y algunos republicanos tratarán de incluir el tema en su plataforma presidencial de 1996. Si estas agendas políticas se imponen, moverán al liderazgo estadounidense hacia la derecha creando un serio clima antimexicano y elevando las tensiones raciales. Esto indudablemente enturbiará las relaciones binacionales.

\section{LA MIGRACIÓN Y EL TLC}

Durante las discusiones para establecer el Tratado Norteamericano de Libre Comercio (TLC) ambos gobiernos se negaron a enfrentar la cuestión de la migración bajo la hipótesis de que el tratado crearía suficientes oportunidades económicas en México que en el mediano plazo frenarian la migración.

Hay muchas reservas de que esto suceda, y aun si la premisa fuera correcta, indudablemente que esto no sucederá de inmediato. Asumir que la sola creación de empleos es suficiente para que los mexicanos se queden en México, es irreal. El flujo migratorio actual menosprecia los empleos con bajo salario. Como vimos más arriba, un elevado porcentaje de los migrantes estaban empleados en el momento de migrar y es difícil saber cuánto tiempo pasará, si es que sucede, hasta que se cierre el diferencial salarial entre ambos países como para dejar de hacer atractiva la migración.

Tal vez sea irreal asumir que los salarios se disparen como resultado del TLC, toda vez que los gobernantes mexicanos no dan indicaciones de dejar de considerar al salario como factor inflacionario. Tal y como se ven las cosas, dos años de TLC y una política monetaria neoliberal han sido desastrosos para la economía en general y el empleo en particular. La patrulla fronteriza sostiene haber aumentado el número de detenciones en 1995, aunque esto puede ser consecuencia de un incremento en el número de agentes.

Para que el TLC impacte la migración tendría que modificar drásticamente las condiciones de la economía y el empleo, para provocar un cambio sustancial y esto, tal vez sea mucho esperar. De cualquier manera, aun si el cambio se iniciara en breve, su efecto se sentiría solamente después de unos cuantos años y mientras tanto hay que actuar frente a los millones que continuarán migrando.

\section{CÓMO RESPONDER A LA MIGRACIÓN}

Las decisiones tomadas entre México y Estados Unidos, cuyo efecto seria entre otros frenar la migración, no han funcionado. Podemos tomar como ejemplo las industrias maquiladoras que emplean alrededor de 600000 
personas. Tienen poco impacto sobre la economía mexicana como para diversificar las economías locales, dinamizándolas para incorporar la mano de obra disponible, porque el ingreso se vuelve en gran medida como consumo a Estados Unidos, con lo cual su potencial reproductor es casi nulo. Estas empresas integran un escaso $2 \%$ de productos nacionales (básicamente empaques) y al evadir regulaciones ambientales han generado un deterioro ambiental de elevada magnitud (Baker, 1991). Tienen una elevada rotación de personal, tal vez porque la gente entra a trabajar para reunir dinero y pagarle al coyote para cruzar la frontera, ${ }^{24}$ han provocado gigantescos cordones de miseria a lo largo de la frontera México-Estados Unidos y una creciente descomposición social y fracasaron como factor de retención.

La migración de México hacia los Estados Unidos ya se ha convertido en una cuestion de seguridad nacional porque responde a serios desequilibrios económicos en México, está creando presiones inéditas en Estados Unidos y es una fuente de irritación constante entre ambos países. Frenar la migración mexicana con medios policiacos implica crear presiones económico-políticas en México, con un elevado potencial desestabilizador que indudablemente se revertirá sobre Estados Unidos, implicando eventualmente, entre otras, mayor migración indocumentada. ${ }^{25}$ Involucrarse en una carrera de mayor despliegue policiacomilitar para frenar la migración puede tener implicaciones políticas y sociales muy serias.

La migración debe enfrentarse con una nueva estructura de pensamiento, nuevas definiciones de progreso y un nuevo paradigma para las relaciones entre México y Estados Unidos. No debe enfrentarse con propuestas basadas en supuestos de dudosa viabilidad y mucho menos tomando decisiones con un elevado costo social, económico y ambiental.

\section{RECOMENDACIONES}

\section{Hacia un programa de desarrollo regional}

México debe abandonar la política de no definir una política y establecer un proyecto de desarrollo económico acelerado en los estados expulsores de población. Solamente la creación de oportunidades económicas de alto

\footnotetext{
${ }^{24}$ Hay quien considera que Ja rotación se debe a que las empresas compiten quitándose personal. Si esto es cierto, habría que preguntarse por qué razón no han logrado ampliar las bases de empleo permanente.

${ }^{25}$ A partir de la crisis de diciembre de 1994 múltiples voces en Estados Unidos han expresado su temor de que una de las consecuencias sea el aumento en la migración.
} 
nivel y una elevación del nivel de vida en las entidades de origen de los migrantes logrará frenar la migración. ${ }^{26}$ Este programa debe, entre otros, reorientar la economía hacia la creación de empleo bien remunerado y de trabajo intensivo, eliminando rigideces salariales, promoviendo pequeñas empresas, asistencia al sector informal y mejorando la formación educativa y profesional. $^{27}$

Estados Unidos tiene que entender y aceptar que son parte y causa de la migración indocumentada y que tiene que ser parte de la solución. Para reducir el nivel de tension y violencia fronteriza el Southwest U.S.-Mexico Border Policy Group creado en El Paso, Texas sugirió que se movieran los controles migratorios 25 millas al norte, de tal forma que la franja fronteriza se convirtiera en una zona de amortiguamiento, donde la fuerza de trabajo fluyera libremente y se creara un potencial económico que elevara el nivel de vida y ampliara las oportunidades económicas a lo largo de la franja fronteriza.

AI moverse los controles migratorios se desmilitarizará la frontera y se dejará de invertir en barreras antimigración. Los recursos ahorrados al retirar agentes policiacos y dejar de construir muros, podrán ser invertidos en desarrollo infraestructural fronterizo incentivando el crecimiento económico. Esto permitirá que la frontera eleve su capacidad competitiva, pueda atraer mayor inversión e irradie efectos de desarrollo a otras regiones.

Como complemento del programa de desarrollo económico, ambos países deben firmar un tratado de migración que facilite la entrada a Estados Unidos de aquellos mexicanos que no se beneficien de inmediato con el programa de desarrollo económico regional. La cifra cubierta por el tratado puede ser elevada al principio, por ejemplo 500000 personas, e ir disminuyendo conforme mejoren las condiciones de vida en México. Podemos asumir que conforme el programa avance cada vez serán menos los que deseen migrar. Los migrantes protegidos por este tratado podrán encontrar empleos y no ser molestados por la policía fronteriza, tendrán condiciones de vivienda y salud adecuadas y los impuestos que generen podrían aplicarse para ampliar el programa de desarrollo. México se comprometería a encontrar medidas para absorber nacionalmente a aquéllos que rebasen la cantidad pactada, evitando militarizar su frontera para que no se desarrolle un problema de derechos humanos del lado mexicano.

\footnotetext{
26 Jesús Tamayo coincide con esta postura como lo expresa en su articulo "Contra el flujo laboral, reactivación de la economía mexicana" (1994).

27 Coincido con esta propuesta de Joaquín Arango expuesta en su trabajo: "El 'Sur' en el sistema migratorio europeo. Evolución reciente y perspectivas".
} 
En Estados Unidos el gobierno debe luchar contra la campaña antimigratoria empezando por cambiar el lenguaje de las agencias migratorias, reconociendo las verdaderas causas de la crisis económica y dando crédito a la aportación económica mexicana.

Son censurables e inaceptables las concentraciones de miseria urbana en México y en Estados Unidos. Se debe iniciar un programa para mejorar las condiciones de vivienda de los mexicanos en Estados Unidos. Los migrantes mexicanos que hoy en día viven indocumentados en Estados Unidos deben recibir facilidades para legalizar su estancia y no ser perseguidos como criminales.

\section{Un estatuto de refugio económico para los migrantes}

La migración aun cuando es voluntaria ${ }^{28}$ responde a un complejo cuadro economico en el cual comparten responsabilidad los empresarios de ambos países que han creado históricamente las condiciones de miseria que hoy dejan a millones inermes y sin posibilidades de mejoría.

En la reunión de Río se concluyó que los que deterioran el medio ambiente deben pagar el daño que causaron, justo es trasladar el concepto hacia los seres humanos y exigir que aquéllos que causaron la miseria humana paguen para reparar el daño. Las empresas nacionales, extranjeras y multinacionales que se han beneficiado de la explotación de esos individuos que ahora tienen la necesidad de emigrar, deben cooperar para aliviar la carga que ayudaron a crear.

Si la migración ayuda a la economía estadounidense justo sería que Estados Unidos coopere. Vernez y Ronfeldt (1992) sugieren que un aumento en la inmigración afecta negativamente el nivel salarial. Aun cuando sobre esta discusión bay un debate no resuelto, no hay duda que la migración mexicana ha jugado un papel fundamental para reducir salarios, mantener baja la inflación y sostener la competitividad de Estados Unidos.

La migración es una solución, el problema es la miseria extrema y los empleos mal pagados. Si migrar representa una mejoría, debemos aceptar que la mayor parte de la población mexicana, incluidos los migrantes, está siendo abusada por el sistema económico, tanto en México como cuando llegan a Estados Unidos, donde desarrollan actividades más bajas de las que su calificación amerita y reciben un salario mucho menor del que recibe alguien con su misma preparación siendo ciudadano. La diferencia en la calidad de vida para calificaciones equivalentes entre ambos países

${ }^{28}$ Considero como voluntaria la decisión de emigrar que no se deriva de persecusiones religiosas o políticas. 
es abismal y estimula la migración. Es urgente una armonización global en empleo y calidad de vida.

La comunidad internacional ha desamollado un estatuto de refugio político para aquellos perseguidos por sus ideas políticas, también debe desarrollar un estatuto de refugio económico para aquéllos cuyos sistemas económicos abusan de ellos.

Los mexicanos que hoy viven indocumentados en Estados Unidos deben tener la posibilidad de solicitar asilo económico y recibir facilidades para legalizar su estancia y no ser perseguidos como criminales.

No es sólo moralmente incorrecto tener un país y un subcontinente polarizado por un puñado de multimillonarios y una masa de pobres, sino que es económicamente inviable. Una nueva definición de la migración, acompañada con la apropiada acción gubernamental y del sector privado, puede poner las bases para un futuro promisorio más democrático económica y políticamente.

\section{CONCLUSIÓN}

Considerando la migración mexicana a Estados Unidos como el flujo de un solo país a otro, posiblemente estemos frente al mayor éxodo de la historia. Los números son fríos y aleccionadores, pero puede decirse mucho sobre el drama humano que sufren los que emigran, desterrándose y dejando atrás familia, sociedad, cultura y hasta idioma.

La migración es una cuestión socioeconómica en la cual están involucrados ambos gobiemos. México, porque su población abandona el país y Estados Unidos, porque la condición de miseria mexicana se provoco en parte por el desarrollo de los intereses estadounidenses al sur de su frontera. Esta miseria se está importando a un número creciente de ciudades estadounidenses.

La migración es un tema de roce constante y de enturbiamiento de las relaciones binacionales. Ambos gobiernos deben formular alternativas de solución auxiliados por el sector privado. Ya no es posible aplazar la atención a este problema que sume en la indefensión a millones de personas anualmente y crea roces políticos que nublan el entendimiento necesario para construir un continente y un mundo mejor.

Históricamente los mexicanos sufrieron abusos en Estados Unidos, que ayudaron a elevar la productividad y bajar la inflacion. Este abuso muchas veces tuvo el auxilio de las autoridades migratorias. Estados Unidos continúa implantando soluciones policiacas a este problema social en lugar de generar programas remediadores. Así, encontramos desde discriminación en todos los ámbitos societarios hasta la militarización de 
la frontera entre ambos países con los consiguientes abusos policiacos. $\mathrm{La}$ clandestinidad de Ia migración indocumentada crea una zona de criminalidad y un ambiente de violencia que extiende sus efectos hasta centroamérica, donde los polleros se anuncian en el periódico para con frecuencia engañar y vejar a la gente.

Estados Unidos tiene la capacidad de auxiliar a México para desarrollar alternativas creativas. Idealmente, el avance económico mexicano beneficiará a Estados Unidos y facilitará la creación de una zona integrada sin pobreza que irradiará hacia Centroamérica. ${ }^{29}$

México está registrando en su frontera sur los mismos problemas que Estados Unidos registra en su frontera sur. Para ninguno las soluciones policiacas, parciales y parchadas funcionará mientras no se encuentren soluciones globales que saquen a América Latina de su atraso endémico.

El futuro del continente no mejorará criminalizando los fenómenos socioeconómicos. Los migrantes no son delincuentes, son refugiados económicos. La única solución factible a este problema es generar un enfoque humanista.

29 Autoridades migratorias mexicanas revelan que en 1995 había 42000 salvadoreños documentados en el pais, cantidad que tarde o temprano puede llegar a 500000 indocumentados. 


\section{BIBLIOGRAFÍA}

ACOSTA, Sarah. 1992. "Mexico Inc,, The Corporate Elite". Hispanic Business, agosto.

ARANGO, Joaquín. s/f. "El Sur en el Sistema Migratorio Europeo. Evolución Reciente y Perspectivas", (mimeo).

BAKER, George. 1991. "Mexican Labor is not Cheap", Río Bravo, núm.1, otoño.

BALBOA Reyna, Flor de María. 1991. "Antes de que la verdad Irrumpa...", La Jornada Laboral, Agosto 30.

BANAMEX. 1993. Review of the Economic Situation of Mexico, México, D.F., agosto,

CASIO, Luiselli. 1980. El Sistema Alimentario Mexicano (SAM): Elementos de un programa de producción acelerada de alimentos básicos en México, University of California San Diego Campus, Working Papers in U.S.-Mexican Studies, núm. 22 ,

CORRO, Salvador. 1993. "Vertiginoso Crecimiento de la Pobreza en el Sexenio", Proceso, núm, 854, marzo 15.

DIEZ-CANEDO, Juan. 1984. La migración indocumentada de México a los Estados Unidos. Un nuevo enfoque. FCE, México, D.F.

FARÍAS, Luis M. 1992. Asílo recuerdo. Testimonio político, México, D.F. FCE.

FRIEDEN, Jeffrey A. 1989. "Winners and Losers in the Latin American Debt Crisis" en Barbara Stallings y Robert Kaufman, (eds), Debt and Democracy in Latin America, Boulder: Westview.

GURRÍA, José Ángel. 1991. "Debt Reduction and the "Virtuos Circle"”. El Financiero International, julio 22.

HERNÁNDEZ, Patricia. 1994. "117 mil denuncias de abusos contra Mexicanos en Estados Unidos: SRE", Uno más Uno, 13 de febrero.

HERRERA Sobek, María. 1979. The Bracero Experience. Elitelore versus Folklore, Los Ángeles; University of California Press, UCLA Latin American Studies Center Publications.

IZQUIERDO Escribano, Antonio. 1992. "La inmigración en la España de 1992", (mimeo).

LOZANO Ascencio, Femando. 1993. Bringing It Back Home. Remittances to Mexico from Migrant Workers in the United States, University of California, San Diego, Center for U.S.-Mexican Studies.

MARTÍNEZ, Ifigenia. 1989. Algunos efectos de la crisis de la distribución del ingreso en México, UNAM, México, D.F. 
McCLINTOCK, John M. 1993. "Rich Man's Dinner Proves Mexican Presidency is out of Touch", El Paso Times, marzo 22.

MORALES Rico, Reyes. 1993. "Pide Mayor Presupuesto la ARDF Para Gasto Social y de Salud", El Financiero, abril 8.

RODRÍGUEZ Castañeda, Rafael. 1993. "Borrego, 29 magnates y el Presidente de la República". Proceso, núm. 853, marzo 8.

SAINZ, Pedro. 1993. Informe sobre la magnitud y evolución de la pobreza en México en el periodo 1984-1992, INEGI-CEPAL, México, D.F.

SANTIBÁÑEZ, Jorge, Javier Valenzuela y Laura Velasco. 1993. "Migrantes Devueltos por la Patrulla Fronteriza", ponencia presentada en la conferencia Facetas de la violencia fronteriza, Universidad de Texas en El Paso, Mayo 3-4.

SCHMIDT, Samuel. 1991. The Deterioration of the Mexican Presidency, Tucson, University of Arizona Press.

- 1996. "Detentions et deportation a la frontiere entre le Mexique et les Etats-Unis", Cultures \& conflicts. Les camps de ritention aux fronihres occidentales: surveiller enfermer, refouler, núm, 23.

SCHMIDT, Samuel y David Lorey, 1994. "Policy Recommendations for the Metropolitan Area of El Paso-Ciudad Juárez". PROFMEX Urban Studies Series. El Paso Community Foundation-Center for Inter American and Border Studies, UTEP.

Servicio de Inmigración y Naturalización de los Estados Unidos y Departamento de Justicia de los Estados Unidos. 1993. SIN Fact Book. U.S. Government Printing Office.

Servicio de Inmigración y Naturalización de los Estados Unidos (SIN). s/f, Recent Upsurge in Apprehensions of Mexican Nationals for Illegal Border Crossings in the San Diego Sector: A Look at Causative Factors, Mexico City Office, American Embassy.

SIMON, Julian L. 1993. "The Nativists Are Wrong". The Wall Street Journal, agosto 4.

SMITH, Clint. 1993. La frontera que desaparece. UAM-Universidad de Califomia-Los Ángeles, México, D.F.

SPEARS, Gregory. 1994. "Feds Offer Plan To Combat Billions in Welfare Fraud", Albuquerque Journal, abril 20.

TAMAYO, Jesús. 1994, "Contra el flujo laboral, reactivación de la economía mexicana", La Jornada Laboral, noviembre 24.

VERNEZ, Georges y David Ronfeldt. 1991. "The Current Situation in Mexican Inmigration", Science, Vol. 251, marzo 8.

WORLD BANK, 1991. Urban Policy and Economic Development. An Agenda for the 1990's. Washington, D.C. 